\title{
Working later in the USA and Ireland: implications for precariously and securely employed women
}

\author{
Á. Ní Léime ${ }^{1 *}$ and Debra Street ${ }^{2}$ \\ ${ }^{1}$ Irish Centre for Social Gerontology, National University of Ireland, Galway, Republic of Ireland and ${ }^{2}$ State \\ University of New York at Buffalo, USA \\ ${ }^{\star}$ Corresponding author. Email: aine.nileime@nuigalway.ie
}

(Accepted 4 April 2018; first published online 17 July 2018)

\begin{abstract}
Policies to extend working life (EWL) assume homogeneous workers face similar choices about working longer: this may be difficult for women, workers in physically onerous jobs or in low-paid precarious employment. Work-life trajectories are gendered; women interrupt employment and pension-building to provide care. There is occupational variation in capacities to prolong working lives: physically demanding jobs cause work-related health deficits. The precariously employed cannot contribute regularly to pensions and may face age discrimination. This research provides an inter-occupational and cross-national dimension to EWL research, comparing women teachers and health-care workers in the United States of America (USA) and Republic of Ireland. It documents intra-cohort distinctions that emerge among women when considering educational opportunities and occupational tracks expressed in lifecourse trajectories and accumulated capacities for extended work. Analysis draws on interview data from ten teachers and ten healthcare workers in each country, comparing the implications of EWL policies for women workers: in precarious versus secure occupations and occupations with different physical demands. It reveals work-life trajectories leading to poorer financial and health outcomes for older health-care workers, especially in the USA. Most women (regardless of occupation or country) opposed extending working life, with concerns ranging from health status and ability to work to the desire to have healthy years in retirement. The most important distinctions are between the occupational categories considered, rather than cross-national differences. Implications for national and work-place policy and research are considered.
\end{abstract}

Keywords: extended working life; women; home health-care workers; teachers; older workers; precarious employment; secure jobs; lifecourse perspective

\section{Introduction}

International organisations have advocated and individual governments have introduced policies designed to extend working life (EWL) to reduce the costs of state

(C) Cambridge University Press 2018. This is an Open Access article, distributed under the terms of the Creative Commons Attribution licence (http://creativecommons.org/licenses/by/4.0/), which permits unrestricted re-use, distribution, and reproduction in any medium, provided the original work is properly cited. 
pensions (Organisation for Economic Co-operation and Development (OECD) 2006). These EWL policies include raising state pension ages, privatising pensions and increasing individual responsibility for later-life income - a set of policies characterised as benign (given greater longevity) and inevitable (given population ageing). Despite the profound change in the contracts of states with their citizens, EWL policies have been imposed with little attention to their impact on individuals with varied life circumstances. The policies tend to be one-size-fits-all, despite men and women and workers in different occupations having very different work-life trajectories; that precariously employed and low-wage workers have deeper needs for secure state pensions and different capacities to save privately compared to securely employed higher paid workers; or that physically demanding jobs create higher risk of developing chronic health conditions by or before traditional retirement age. This paper aims to address such oversights using data from recent comparative fieldwork about EWL, focusing exclusively on older women workers in the Republic of Ireland and the United States of America (USA). Recent research on the national policy changes involved in EWL (Ní Léime and Street 2016) demonstrates that the costs and benefits of EWL are unequally distributed by gender and across occupations, underscoring the need for more finely grained research about individuals with varying lifecourse trajectories and in different employment situations. This research explores the circumstances of older women workers in two occupations - health care (physically demanding and often precarious) and teaching (physically less demanding and secure) - in two liberal welfare states.

The women's experiences occur in nation-specific policy contexts, shaped by myriad lifecourse processes, occupational characteristics and employment conditions. Earlier we noted the tendency of policy makers to assume universal workers ungendered, unraced, unclassed - who could choose to work longer and be more self-sufficient, if only they would. But because assumptions of homogeneity do not hold, the EWL policies based on them are fundamentally flawed. Earlier work on EWL (Ní Léime et al. 2017) has typically compared women and men. In contrast, this research focuses exclusively on women, in order to understand better how EWL policies interact with lifecourse trajectories to create varied experiences and perspectives among older women workers in different occupational contexts and countries. Our findings indicate that occupational differences are even more important than are cross-national differences, reflecting how women's gendered lifecourse experiences and employment shape perspectives on extending work. Workers in physically demanding jobs and those with lower socio-economic status are more likely to develop chronic health conditions earlier (Marmot and Bell 2010). Although we make no claims of fully intersectional analysis (see Duffy 2005), we offer more nuanced understanding of EWL for women with different life chances, occupational circumstances, income levels and job security.

\section{Policy context in the USA and Ireland}

The USA has an older population and introduced EWL policies earlier than Ireland. Trends towards occupational pension privatisation started in the 1980s, mandatory retirement at age 65 was abolished and recent trends show Americans working to older ages (Lain 2012). The US government gradually 
increased the 'normal' age for entitlement to full Social Security benefits to 67. In fact, the functional age for full Social Security retirement benefits is 70 . The higher age matters, because Social Security benefits continue to increase in the three years between the 'normal' retirement age and age 70 (Munnell 2013). This means that 70 is the de facto age for entitlement to full Social Security benefits, rather than the 'normal' retirement age of 67 (Street and Tompkins 2017). Ireland has a younger population and introduced EWL policies relatively recently, increasing the age at which people qualify for the state pension to 66 in 2014 and announcing increases to 67 in 2021 and 68 in 2028 for all workers (Ní Léime and Street 2016). Recent Irish pension reforms also increased the number of contributions required for workers to qualify for the contributory state pension, linking state pensions even more closely to formal labour market participation (Duvvury et al. 2012).

The USA has strongly encouraged the privatisation of pensions since 1981 (Russell 2014), a process long-recognised as being disadvantageous to women, who are typically in low-paid employment and cannot afford to contribute much to private pensions (Ginn and MacIntyre 2013; Ginn, Street and Arber 2001). Ireland followed suit in the 2000s. The trend has been to individualise pensions, with workers increasingly encouraged to save in tax-advantaged pension savings schemes such as US 401(k)s and Irish Personal Retirement Savings Accounts. These tighter links between pension eligibility and the contours of paid work over the lifecourse disadvantage many women, who are still more likely to have periods out of full-time employment to care for children and family members (Ginn, Street and Arber 2001; Ní Léime et al. 2017).

EWL policies occur within evolving employment and pension structures. Internationally, stricter criteria for accessing disability benefits have accompanied the introduction of these policies. Both countries have sizeable gender pay gaps: 18.1 per cent in the USA and 14.4 per cent in Ireland in 2015 (OECD 2018). Women's lower pay is due to both vertical (concentration into low-paid occupations such as caring) and horizontal segregation (concentration in the middle and lower roles in organisational hierarchies) (D'Addio 2015). Gender pay gaps in employment translate into even higher gender pension gaps between women and men in both countries, at just under 35 per cent. This pension gap is partly due to lower lifetime earnings and the expectation in both countries that women are the primary providers of unpaid care, contributing to periods out of the formal workforce (Dewilde 2012; Ní Léime and Street 2016).

Although individual employers may choose to provide benefits, Americans have no paid statutory maternity or paternity leave, although women working in organisations with $50+$ workers are entitled to 12 weeks of unpaid maternity leave (Street and Tompkins 2017). Comparatively speaking, Ireland has generous paid maternity leave of 26 weeks and two weeks of paid paternity leave. In Ireland, the Homemaker's Scheme gives women pension credits for years spent working unpaid in the home, while pension credits for unpaid care are not available in the USA. However, the 35 years of work credits counted towards Social Security indirectly provides some allowance for time spent in unpaid care, but not usually enough to cover the periods actually encumbered (Ní Léime and Street 2016). More American women than men depend on Social Security for all or most of their retirement income. Similarly, Irish women are more likely to depend on 
the lower non-contributory state pension than the contributory pension, which is work-related. We take as given that normative gender roles and structured inequalities in employment contribute to gendered outcomes associated with EWL and retirement. While the foregoing documents several ways that processes associated with employment and EWL are gendered, it does not consider intra-cohort variation among women in different circumstances. For example, older African American women are more likely than white women to be entirely dependent on Social Security and to be employed in low-paid occupations such as home health aides (Harrington Meyer 2013). They are also more likely to be single or divorced, raising children with little support, with profound effects on the implications of EWL.

\section{The lifecourse and EWL}

A lifecourse framework provides an analytic lens for understanding the implications of EWL within and across cohorts. The lifecourse perspective focuses on trajectories, transitions and turning points in individuals' work-life narratives. Transitions may be from school to work or further education, from work to unpaid caring roles, returning to work and moving from work to retirement. Transitions are negotiated in the context of societal norms, the person's own degree of agency, linked lives (influence of family and friends), location in time and space, and/or institutional environments (Giele and Elder 1998; Grenier 2012). Turning points have lasting effects on subsequent trajectories. They may include personal events such as parenthood, illness or job changing, or more macro-societal events such as the global financial crisis, policy reforms and unemployment rates. The theory of cumulative dis/advantage posits that starting off in life with few/many resources tends to become exacerbated across the lifecourse (Dannefer 2003), with relatively disadvantaged people falling further behind over time. In the context of this work, family circumstances, whether working class or middle class, Irish or American, influence early adulthood transitions that, in turn, shape subsequent life trajectories for older women. These processes unfold through occupational and educational opportunities, characteristics of family formation and motherhood, secure versus precarious employment, and work in occupations with different physical demands. How do advantages and disadvantages accumulate for health-care workers (who begin with relatively few resources) and teachers (who start off on a firmer footing)? In both instances, early adulthood transitions associated with school-leaving and family circumstances represent distinctive turning points that influence later worklife trajectories implicated in EWL. The health of workers in lower socio-economic status jobs is adversely affected at earlier ages than those in well-paid jobs, making it more difficult for them to continue working into older age (Marmot and Bell 2010). Even without work-related ill-health, physical strength declines with age, creating a mis-alignment of work demands and work-ability for older workers in physically demanding jobs.

Health-care workers provide a window into the circumstances of precarious and physically demanding employment, while teaching offers insights into more secure and less physically demanding jobs, highlighting differences in lifecourse-related risks and rewards among older women in EWL regimes. 


\section{Health-care workers}

Health-care sectors in both the USA and Ireland are large and growing employment sectors. Health occupations range from neurosurgeons, to nurses, to custodial workers. Our focus is health-care workers in personal care, one of the fastest growing job categories across wealthy countries - an occupational response to population ageing. In the USA, state governments increasingly recommend less-expensive community-based care (Folbre 2012; Stacey 2011), contributing to job growth. Research on the experiences of US home health-care workers highlights their low pay, and sometimes dangerous and usually precarious conditions of employment (Folbre 2012; Stacey 2011; Stacey and Ayers 2015). Work is physically demanding and may involve transferring clients from bed to wheelchair to toilet, creating greater risk of work-related injuries affecting backs, hips or knees than in many other occupations (McCaughey et al. 2012; Stacey 2011). Employers and the state will pay only for minimal time spent with clients, which is stressful for home health-care workers as it violates their norms of care; most feel there needs to be more time to talk to clients (Duffy, Armenia and Stacey 2015; Stacey 2011).

Home health-care workers and care assistants in nursing homes also constitute a rapidly growing occupation in Ireland. Although there is some research on specific groups in this occupation, such as migrant care workers (see Cangiano and Walsh 2014; Doyle and Timonen 2009; Timonen and Doyle 2007; Walsh and O'Shea 2009), there is none specifically on older carers and EWL. Recent research on physiotherapists in the UK provides useful insights into how retirement norms and the health concerns of professional health-care workers affect their views on EWL, but does not explore the additional concerns of health-care workers in low-paid precarious situations (Roy et al. 2018). Despite political rhetoric advocating the superiority of community care, state community care provision is limited and increasingly outsourced to private health-care agencies. State workers are unionised, receiving benefits and pensions, while agency workers do not (Timonen and Doyle 2007). Older Irish women care workers, similar to those in this research, were among the most likely to be dependent on the low state non-contributory pension (Duvvury et al. 2012).

\section{Teaching}

Teaching is a feminised occupation in both countries. It is often unionised, usually well-paid and offers job security for most. Teachers in US public schools typically belong to an occupational pension system. For the women participating in this research, the State Teachers Retirement System incentivised teachers to retire after (traditionally) 30 years of service at age 55 . The replacement rate of the teachers' pension was initially very high - up to 90 per cent - although that has been somewhat reduced in recent years. Public school teachers are often significantly financially better off if they stay long-term in a particular school district to maximise pay and benefits. With no mandatory retirement age in the USA, teachers can continue to work after age 65 if they choose.

Teaching in Irish state schools has also traditionally been a secure job with a relatively generous pension system. Most study participants began teaching when 
pay levels were higher and pensions more generous. However, since 2008, after the period of austerity associated with the global financial crisis, both pay and pension benefits were reduced for teachers. Newer teachers now work for lower pay, often on short-term contracts with reduced hours that do not offer holiday pay. Such situations - working on short-term contracts - can last for several years. The length of service required to secure a full pension for Irish teachers is longer than in the USA - usually 40 years. Teaching in Ireland is mostly unionised. They receive advice on pension rights and can buy added years of pension to permit earlier retirement. However, public service employment carries mandatory retirement at 65 years and teachers who work after age 65 must work as substitutes on a daily rate or work in a private school.

Previous research has found that secondary teaching in particular can be psychologically demanding and stressful (Grayson and Alvarez 2008; Kerr et al. 2011). International evidence shows increasing demands on teachers in terms of paperwork and care for the welfare of students and policies related to child protection, health and safety.

\section{Precarious versus secure work}

The definition of precarious employment is contested, but it is generally agreed to occur when the employee does not have security, or has zero hours contracts, seasonal and/or sometimes part-time work with few or no benefits (Standing 2011; Vosko 2008). Precarious employment contributes to higher turnover among healthcare workers (Folbre 2012; Zeytmoglu et al. 2009). Further, health-care workers may be unable to control their hours of work or to depend on a regular income (Stacey 2011), making regular private pension contributions impossible. Older workers who must seek alternative or replacement employment find it difficult, due (in part) to age discrimination, with robust evidence that older women are especially vulnerable (Neumark, Burn and Button 2015). Difficulty in finding employment can be compounded where workers have developed health problems, whether work-related or otherwise. Finally, previous studies suggest that job insecurity in itself is associated with a higher risk of poor mental and physical health (Burgard, Brand and House 2007; László et al. 2010). Taken together, the characteristics of precarious employment suggest the question: is EWL even possible for many such workers?

\section{Methods}

Data are from a sub-sample of women health-care workers and teachers from a larger purposive sample of 120 older (aged 45+) Irish and US workers (which also included men and professors, not included in this analysis). The sub-sample analysed is 40 older women - ten each health-care workers and teachers, interviewed in the USA and Ireland between 2015 and 2017. Participants were initially approached through unions, personal contacts and placing flyers in workplaces. Snowball sampling was then used to recruit further participants. Interviews were face-to-face, conducted by the first author at locations chosen by the research participants - at their workplace, a location nearby or the researcher's office - and lasted between 
48 minutes and 2.5 hours. All interviews were audio-recorded with the participants' consent. Participants were asked to give an account of their work-life history; their awareness of pensions; their current situation in relation to work, income and health; their views on extending working life; and their plans for retirement.

The first phase of the interview data analysis used a holistic lifecourse framework to analyse interview transcripts, identifying work-life trajectories and assessing issues of timing, location in time and space, agency, duration of employment and linked lives (influence of parents and friends) (Giele and Elder 1998). One analytic focus was early adulthood transitions or turning points and how those shaped later work-life trajectories leading to precarious or secure employment. In the second phase of the analysis, the current circumstances of participants and their perspectives on EWL policies were analysed thematically. Transcripts were first open-coded in an iterative process to identify dominant concepts and organise the interview data. The analysis in this paper used the empirical data associated with themes and concepts associated with EWL. Table 1 shows summary characteristics for the four categories of women workers considered.

\section{Early adulthood transitions and turning points Teachers}

Each US teacher reported being strongly encouraged or fully expected by their families to attend university. Some were specifically encouraged to teach and/or had teacher role models in their family. As one remarked:

I had my grandfather on my mom's side was a Superintendent of Schools. My grandmother was a teacher. On my Dad's side, I have like a second cousin who was the Superintendent of Schools ... There were teachers left and right, so we were always kind of in a family of where education, that was always a viable option. (Edel, US teacher)

Teachers from Ireland offered similar accounts:

I always wanted to be a teacher ... Well, I suppose, like, my uncle is a teacher, my aunts are teachers and I just loved school - I was the greatest swot ever! (Barbara, Irish teacher)

For some teachers, the lack of family role models was not an impediment to career aspirations. Even parents who lacked university or secondary education strongly encouraged or expected their children to attend higher education:

My father actually was working in a factory and he was a carpenter ... and he had never gone to secondary school himself, so that was often touted, 'You know what? Ye'll stay in secondary school because I never got a chance to go to it', that type of thing. (Caitriona, Irish teacher)

American parents offered similarly strong encouragement: 
Table 1. Women aged $45+$, in precarious/secure and physically demanding/less demanding occupations

\begin{tabular}{|c|c|c|c|c|}
\hline & \multicolumn{2}{|c|}{ Health-care workers (precarious, physically demanding) } & \multicolumn{2}{|c|}{ Teachers (secure, physically undemanding) } \\
\hline & USA & Ireland & USA & Ireland \\
\hline $\mathrm{N}$ & 10 & 10 & 10 & 10 \\
\hline \multicolumn{5}{|l|}{ Age group: } \\
\hline $45-54$ & 4 & 3 & 1 & 2 \\
\hline $55-64$ & 2 & 4 & 9 & 8 \\
\hline $65-74$ & 4 & 3 & 0 & 0 \\
\hline Education (highest level) & $\begin{array}{c}\text { High school: } 5 \\
\text { HSD + } 2 \text { years community } \\
\text { college: } 5\end{array}$ & $\begin{array}{c}\text { Primary: } 1 \\
\text { Secondary partial: } 1 \\
\text { Leaving certificate: } 7 \\
\text { UGD: } 1\end{array}$ & $\begin{array}{c}\text { BEd: } 1 \\
\text { BEd + postgraduate } \\
\text { masters: } 9\end{array}$ & $\begin{array}{c}\text { UGD: } 2 \\
\text { UGD + HDIP: } 5 \\
\text { UGD + HDIP + masters: } 2 \\
\text { UGD + } 2 \text { HDIPs: } 1\end{array}$ \\
\hline \multicolumn{5}{|l|}{ Marital status: } \\
\hline Married & 4 & 8 & 8 & 9 \\
\hline Single & 4 & 1 & 2 & 1 \\
\hline Divorced & 2 & 1 & 0 & 0 \\
\hline \multicolumn{5}{|l|}{ Number of children: } \\
\hline 0 & 0 & 1 & 0 & 1 \\
\hline 1 & 0 & 1 & 2 & 1 \\
\hline 2 & 4 & 1 & 6 & 3 \\
\hline 3 & 3 & 1 & 1 & 2 \\
\hline 4 & 1 & 4 & 1 & 3 \\
\hline 5 & 2 & 1 & 0 & 0 \\
\hline
\end{tabular}




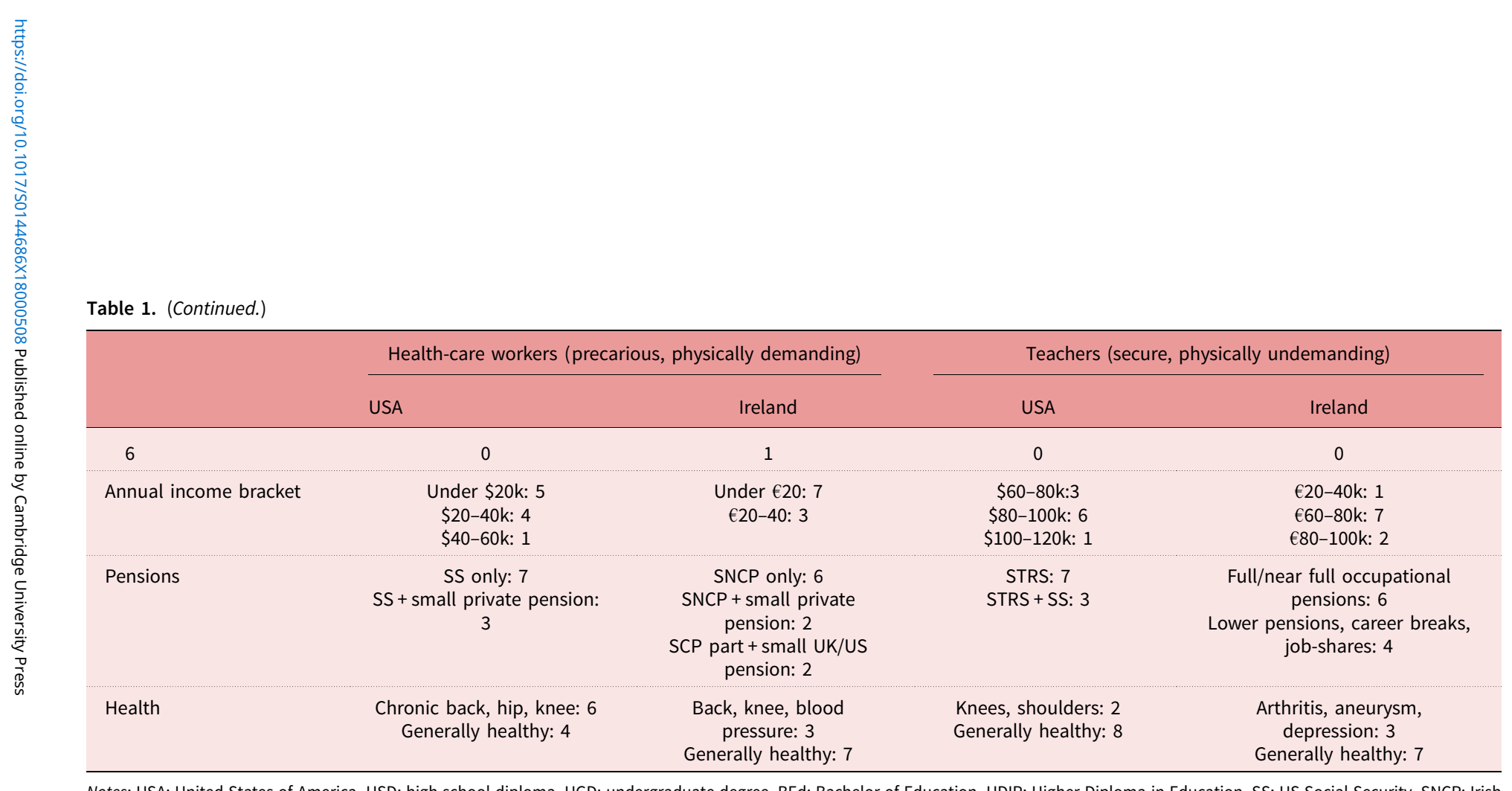

Notes: USA: United States of America. HSD: high school diploma. UGD: undergraduate degree. BEd: Bachelor of Education. HDIP: Higher Diploma in Education. SS: US Social Security. SNCP: Irish State Non-Contributory Pension. SCP: Irish State Contributory Pension. UK: United Kingdom. STRS: State Teachers' Retirement System. 
My father, who never went to college, he worked all his life to send his daughters to college so we would get a good education, and so it was very much promoted in my house and teaching was just the thing I wanted to do. (Cynthia, US teacher)

Teachers in both countries experienced transitions in early adulthood that set them on trajectories to secure future careers, encouraged by families that offered role models and emphasised and/or had resources to support higher education.

\section{Health-care workers}

Health-care workers, by contrast, often lacked parental encouragement to continue in education. Indeed, some did not complete even secondary education. Sometimes there was an expectation of early employment, either because their large families needed money from their wages for support, or because they themselves wanted to earn. For example, one Irish health-care worker (among the oldest in a family of 14) left school at age 13 to work in a local factory:

I thought I would go to work, I would help my mother and father. (Ita, Irish health-care worker (HCW))

For others, university was never even considered:

At that time, third level, wasn't ... well, there was some going to third level -but in our house - Daddy hadn't the money - it just wasn't thought of, at all. (Greta, Irish HCW)

In Ireland, secondary education was fee-paying until 1968; unsurprisingly, two of the older Irish health-care workers left formal education after primary school.

Two US health-care workers attended community college after high school, only to stop when family members (mother-in-law and grandmother, respectively) needed care, reflecting a common pattern among African American care workers (Stacey 2011):

I did two years in college ... My grandmother got diagnosed with pancreatic cancer and there was no one to care for her and we wouldn't just throw her in a nursing home, so I took out of school. (Emma, US HCW)

Three other US health-care workers' education was disrupted by pregnancy. Early transition to motherhood altered adult lifecourses in fundamental and longstanding ways:

Because when I found that I was pregnant, they didn't allow me to go back to school. You couldn't in those days, you couldn't go to school pregnant and if you had a child, you could not go back to school. (Andrea, US HCW)

In some cases, US health-care workers said they tried to get better jobs. For example, one woman who became pregnant in high school tried later to train as 
a nurse. By then she was a single parent and found it too difficult to study and work and care for three children:

You know, but me having three kids, working full time and being to school by eight o'clock every morning, I burned out. And for me to say it, that's the saddest thing that I didn't go back. (Andrea, US HCW)

Still others conformed to the norms in their social circles to leave school and get a job until they got married.

US health-care workers sometimes described taking up care-giving as a natural follow-on to providing (unpaid) family care, fulfilling traditional gender norms. For example, one (of three) US women who migrated to a northern city from the rural South remarked:

People say I chose the profession, but I think the profession chose me as a child because we were care-givers to our grandparents and great-grandparents who were home. And they didn't have, like, potty chairs - like we had chamber pots and stuff that we had to empty them and take food and see that they ate and whatever when we were younger kids in the country. (Andrea, US HCW)

For most US health-care workers, low levels of education led to a trajectory of subsequent low-paid jobs in the services sector, typically working as cleaners in hospitals or in food preparation before ending up as frontline health-care workers. For some, low-paid work was interspersed with periods of unpaid family care (especially their own children), undermining the capacity for continuous employment. The types of service jobs these women held did not offer occupational pensions. Although Social Security provides benefits to dependent spouses, many of the US health-care workers interviewed were divorced or single and fully dependent on their own incomes. Wages were low and there was no surplus to save for a private pension. They expected to depend completely on their own Social Security record for income in retirement.

The Irish health-care workers' employment trajectories were broadly similar to their American counterparts, typically featuring early low-paid jobs in services, manufacturing or clerical work before marriage and motherhood, and later moving into the health-care sector. In many cases, early employment in service industries was followed by up to 20 years out of employment, providing unpaid care for family members - most Irish women had relatively large families. This pattern fit social norms and employment and taxation legislation of the time. Relatively few married women with children were employed in Ireland before the late 1990s. The narratives of the Irish health-care workers reflected societal gender norms of the day in Ireland, for women to get married, have children and work unpaid in the home:

I had no career plan. Well, I probably wanted to get married and maybe have children, you know. (Ita, Irish HCW)

Most Irish health-care workers expected to depend on the state non-contributory pension. Although it is relatively low, it is more than the Social Security payments 
that US health-care workers would receive. However, unlike many of the US healthcare workers, most of the Irish group were married and expected to share in their husband's occupational pension (where it exists) or the state pension.

Irish women typically took up health-care work after spending years working at home. Several expressed their desire to stay at home with their children, in keeping with social norms at the time:

I always said that if I ever had kids I was staying at home no matter if I was living on bread and butter every day I was going to mind them. (Gillian, Irish HCW)

Interviewees noted that staying at home with children is not possible for young Irish women now - both parents need to work to pay high mortgages. The healthcare workers interviewed usually started work when their children were at primary or secondary school age. Prior to this, some had provided child care privately for local children in their own home. Others had voluntarily visited older people in their community and were later asked to provide care on a paid basis, either by the person's family or a community organisation. Some said they pursued healthcare work because they were unqualified for anything else:

I was at home a long time and ... I suppose I hadn't sort of done anything in between except look after children. (Alice, Irish HCW)

I was quite daunted, because I was out of the workforce forever but I chanced it and went in. (Clara, Irish HCW)

Although several Irish health-care workers had wanted to be nurses at schoolleaving, they either received little support or guidance at school or home, or did not get the requisite results in examinations and became discouraged. One said her parents and teachers had no background knowledge in nursing in any case. As an only child, her father wanted her to work locally. Others, too, commented that parents did not know enough about further education to provide guidance.

Typically, health-care workers married and/or had children at earlier ages than counterpart teachers in both countries, and had larger families. The varied early adulthood transitions between teachers and health-care workers created distinctive work-life trajectories and income and pension prospects as they approached traditional retirement age. For health-care workers, the work itself was physically demanding and had health implications that teachers could mainly avoid in their less physically demanding occupation. Over half of the US health-care workers interviewed were single parents with larger families of children, and sometimes grandchildren, to support single-handedly. It was difficult to meet day-to-day expenses from wages in low-paid work, much less earn enough to pay into private pensions. Most of the US health-care workers in the sample are African American and the incidence of marriage is lower for African American than for white women. Although there are insufficient data to do justice to an analysis of the intersection of race with gender and age, race/ethnic status is another consideration for understanding the implications of EWL policies. Irish health-care workers often married 
young and had large families, creating a distinctive work-motherhood-work trajectory associated with income and retirement vulnerabilities.

US teachers typically had smaller families than did health-care workers, and most were married (see Table 1), with much larger household incomes. In Ireland, health-care workers also tended to have larger families than teachers. However, they differed from the US health-care workers in that most Irish women remained married and expected to share in their husband's pensions. Still, Irish health-care workers' husbands were more likely to be precariously employed than teachers' husbands (most of whom were in professional well-paid employment), with lower household incomes and smaller pension entitlements.

\section{Current occupational circumstances}

\section{Health-care workers}

Most US health-care workers in the study were home health aides, working in client's homes, mainly providing personal care such as bathing, dressing and meal preparation. A few were certified nursing assistants, doing similar work, but in nursing homes. The Irish health-care workers were similar; those working in the community may be called 'home helps' or 'carers' and those in nursing homes may be referred to as care assistants. Although such health-care workers in the USA and Ireland do not typically provide medical care, they assist in monitoring medication and maintaining safe, healthful environments. Because we are making no analytic distinction between home health providers and nursing home workers, all are referred to simply as health-care workers.

Working conditions were unfavourable, with low pay, ranging from US $\$ 8$ to $\$ 12$ per hour. Most (nine) earned less than $\$ 40,000$ annually, despite most working the equivalent of full-time hours. Community health-care workers were paid hourly, with (usually) no benefits or vacation leave. As one home care agency worker put it:

They offer no health insurance. You don't have personal days. You don't get compensated for vacation days. If you don't go to work, you don't get paid. It's no fairness in that field. (Jane, US HCW)

Employment was becoming increasingly precarious for health-care workers employed by private agencies, most of whom were not unionised. Some recalled having benefits such as paid time off or occupational pensions in the past, but such benefits had recently been withdrawn:

We used to have PTO [paid time off] here. They took it [away] last year. (Bella, US HCW)

Certified nursing assistants working in US nursing homes or hospitals tended to have somewhat better pay, employment contracts and benefits, and more predictable hours (shifts) than home health aides working for private home health agencies in the community, and some were unionised.

In Ireland, most health-care workers interviewed earned less than $€ 20,000$ per year. There were differences between community health-care workers employed 
by the Health Services Executive (HSE) (government employees) and those employed by private agencies. Those employed by the HSE tended to have higher hourly pay (€12-15 per hour) and to receive allowances for travel. Some had contract hours and were paid for training, which was provided free of charge. The HSE employees interviewed were union members hoping to negotiate better conditions. In contrast, women working for private agencies had lower hourly pay ( $€ 10-12$ per hour) and paid for their own travel and car upkeep. As one woman noted:

The money is ridiculous ... €11 [per hour] ... You have to put in your own petrol ... If you were getting driving expenses at least ... it would cover the wear and tear of your car because you're going into little roads and you're going down potholes ... I had to change tyres twice a year. (Greta, Ireland HCW)

Private health-care workers in Ireland also had to pay for their own (compulsory) training. Working hours were often dispersed throughout the day, with many health-care workers working on and off from, say, 7.30 am to $9.30 \mathrm{pm}$. They were typically under time pressure, often allotted only 30 minutes to carry out tasks which, by any reasonable measure, would take longer. This was stressful for many health-care workers who worried that they (clients) needed more time, as they were often lonely and health-care workers might be their only visitors. Both private and HSE employees may continue to work after traditional state pension age. HSE employees are also offered the opportunity to pay into a pension scheme, while none of the private agency employees interviewed were offered this opportunity.

Pay and working conditions were better in Ireland than in the USA. Even the agency workers in Ireland were entitled to some paid time off, based on the number of hours they worked, while in the USA, there was no paid time off in most of the private agencies. What the jobs shared in common in both countries was uncertainty about hours of work, relatively low levels of pay and the heavy burden of care expected of the health-care workers. Most health-care workers in both countries were very attached to their clients and felt the job was personally rewarding, though not adequately compensated.

\section{Teachers}

American women who taught in public schools had good salaries, with even the lowest paid teachers (in the $\$ 60-80,000$ annual income bracket) out-earning the highest paid health-care workers. Most earned $\$ 80-100,000$ annually. All had job security, long holidays and access to a good occupational pension - the State Teachers Retirement System - and all were union members. Most Irish teachers also had good salaries (with most earning €60-80,000 annually), job security and were union members - although one teacher hired in the aftermath of austerity policies was low paid. Teachers in the USA and Ireland with relatively lower salaries usually had moved jobs, retrained or started teaching later.

The two occupational categories considered here - health care and teaching both represent feminised occupations. Women were, in part, sorted into very 
different employment circumstances by early adulthood transitions, leading to very different occupational experiences. Differences in work-life trajectories influenced important outcomes for older women workers, including differences in health and perspectives associated with EWL.

\section{Health}

In both countries, some health-care workers described chronic health conditions that either currently limited their ability to work or would do so in the future. Some workers reported that work was the cause:

That makes it harder for us when we have to physically move these people, and they're like dead weight, and a lot of us have bad backs ... I have a bad back. Yes, and it's from working and being a nursing assistant. (Holly, US HCW)

Another US home health-care worker expressed concern that she would be unable to continue as a care worker as she aged:

I have a limitation. I don't overdo it. Like I said, I don't lift patients. I just don't do it because that's not good for your back, your legs, any part of your body. But yes, as you get older, if your health fails, yes, you're not gonna be in this job. (Elspeth, US HCW)

Although nursing home work was somewhat better paid, the burden of heavy physical work motivated some to move to home care as they grew older. Nursing home work became physically impossible to continue, especially with increasingly high patient to staff ratios associated with cutbacks. As one woman put it:

When I was younger, I never would work in people's homes. It didn't pay enough. I couldn't afford to work in home care, but now that I'm older and my knee hurt and stuff ... So, I go to home care. (Holly US HCW)

For health-care workers with physical deficits, EWL might involve changing jobs, such as moving from a nursing home to the even more precarious home health-care setting - or continued work might not be an option at all, at least in the health-care sector.

Irish health-care workers recounted similar experiences. For example, one worker provided care for a client who regularly required transfer from a wheelchair to a car, injuring her back:

I have a bulging disc that's on the nerve. Do you know the sciatica nerve and it's going down my legs and I noticed this about two years ... it's probably, it's probably pushing and pulling and ... lifting ... Yeah, lifting and all that like, you know? (Freda, Irish HCW)

Similar physical injuries affected the ability of health-care workers to carry out their day-to day work, particularly as they get older: 
My back hurts. My legs hurt. Sometimes it's hard for me to bend over just to pick up something off the floor and I'm 53. And it's just because I have a bad back. I have a pinched nerve. (Jenny, US HCW)

If workers are struggling with work-related physical wear and tear in their fifties, it will be difficult to extend their work to age 65 , much less to age 67 .

By contrast, most of the teachers in both countries reported being physically healthy:

I mean both my husband and I are really pretty healthy, so but I guess if that changed, that might influence ... [the timing of retirement]. (Heloise, US teacher)

However, some teachers noted that teaching took a different toll, as it was emotionally and psychologically taxing:

I think the stress and the amount of mental and emotional energy that you have to keep putting out every day wears on you a little bit more. I think your energy level diminishes ... every teacher I've ever known, by the end of their career ... they're going, 'I'm just tired. I'm just tired.' (Jocelyn, US teacher)

Irish teachers in primary schools said the job could be stressful and that teaching young children required a lot of energy:

You have to be ... physically on top of your game, you know for teaching. It's not you're not sitting down at a computer, you have to be very physically well as well as mentally; you have to be a very physical person. You do a lot of jumping around to be a good teacher. (Bella, Irish teacher)

Despite emphasising the occasional physicality of their jobs, none of the teachers in either country reported that their physical health had been compromised by the tasks they had to do to teach, while the opposite was true for the older women working in the health-care sector.

\section{Precarity versus security \\ Health-care workers}

Irish and US health-care workers commented that they could not depend on stable income from week to week:

Right, we'll say, I'm working 20 hours this week. Well now, if one of my patients ... has to go to hospital, well then, those hours are gone from me, until they come back out - or heaven forbid, somebody should pass away, well you're down somebody and you know it may be a while before ... So, it's not steady and you're not guaranteed your [weekly income]. (Helen, Irish HCW)

Such undependable incomes also meant that health-care workers were unable to make regular contributions to private pensions and thus they expected to depend either on US Social Security or the means-tested Irish state pension in retirement. 
Health-care workers in both places were also sometimes under-employed, depending as they did on employers for new clients:

I wouldn't mind getting more hours, working more maybe would help me buy a car and pay a lot of bills I need to pay ... when people get sick and go to hospital, your case ends there and it doesn't pick up until they come from the hospital and call back to get ... the service back. (Debby, US HCW)

US health-care workers reported that some agencies were unsound and could close down unexpectedly, leaving them suddenly unemployed:

Either they [home health agencies] closed down or I would work, go get my check, go take it to cash it and they had insufficient funds. So after that happened say two or three times, I had to let the job go because I'm working for nothing. (Ellie, US HCW)

Episodic employment, where workers have no control over the availability of work assignments, hours or sometimes even receiving pay for work already performed, does not lend itself to pension-building.

\section{Teachers}

All of the US women teachers out-earned even the highest paid US health-care workers and were mostly satisfied with their pay:

I see nothing wrong with the pay ... The benefits are good. (Deborah, US teacher)

Although some would have preferred more frequent raises, or believed teaching was paid less than some other professions, teachers generally valued their job security:

Having my father have been a teacher, I know there's more financial security if you have tenure, and that actually worked out very well because only a year after I got my tenure, we had a huge financial crisis in the District and they were laying off a good number of teachers, but because I had been tenured, I actually jumped above teachers who had been hired before me who had never gotten their Master's degree. (Hope, US teacher)

Most anticipated managing well on their available income in retirement, given that all had a substantial pension from the State Teachers' Retirement Scheme, plus some would also receive Social Security benefits. Although the State Teachers' pension has been reduced in recent years, and teachers had to work longer to receive a full pension, it still offered a generous replacement rate of 78 per cent after 35 years of work, at age 65. Those expecting lower pensions were typically 'trailing spouses' who took breaks to support husbands' careers, or who started teaching careers later. One mentioned the possibility of negative financial impacts in retirement in the aftermath of divorce. Even among securely employed teachers, individual factors such as emigrating, prioritising a husband's career or marital breakdown could undermine income security. 
Similar to American teachers, many Irish teachers valued their secure jobs:

Very important ... permanent, pensionable - very important! (Della, Irish teacher)

Most also expected to be comfortable in retirement:

The pension scheme is good, yeah, it is. So we are lucky and I know we are lucky. We are both aware that we are lucky we are able to retire. (Alice, Irish teacher)

The exceptions are those who started teaching later, under less favourable austerity conditions, or who moved country and had to re-train because their US teaching qualifications are not accepted in Ireland. Among the few Irish women who were main breadwinners (because their husbands were unemployed), there were worries about sufficient income in retirement, since current income and future pensions were relatively low - although not as low as for Irish health-care workers.

\section{Attitudes to EWL}

US health-care workers tended to view increases in the age for eligibility for full Social Security benefits negatively. They specifically referred to the physical demands of work as a barrier to working longer:

Okay now this, I don't mind doing this, but at 65, I don't think that this is what I want to do. I would want to be doing something less physical, and if I am doing something then less physical, I wouldn't mind. (Debby, US HCW)

Many felt that working past the age of 65 should only be by choice, not something that workers were expected or required to do:

No. No. I think it should stay the way it's been, 65, and if you're able to keep working, that's a choice you should be able to make, not ... standard. (Holly, US HCW)

Several health-care workers in both countries were extremely critical of the prospect of EWL because of the high number of years they would already have worked, even before the age of 65 . As one Irish woman observed:

I think that is absolutely the worst decision that has been made in a long, long time, because say a person of 60 ... 66 is pension isn't it now? Your average person at 66 will have worked for 40 odd years. Now, let no-one tell me that somebody who has worked for 40 , or sometimes 50 years, people start at straight out of national [primary] school working, nobody can tell me that they're not ready to retire, and well retire, at 66 and I think it's ... actually very cruel on the part of the government. (Bridget, Irish HCW)

Most health-care workers thought there should be a choice around retirement age, with some even advocating a lower age: 
No, I would love it if the retirement age was 60 - that you could voluntarily - you could retire at 60 . Now for those who wanted to go on to 70 , fair enough, but that you could retire at 60 . (Hilda, Irish HCW)

US and Irish health-care workers alike expressed the view that they should have some healthy years in retirement after a lifetime of hard work, and resented the extra years that raising state pension age imposed:

You've put so many years, your good years in, and you need to be able to enjoy your retirement and it shouldn't just be for the wealthy, I'm sorry. It should be for everyone. Everyone who has gotten out and worked hard should be able to enjoy their retirement. (Emma, US HCW)

Teachers also had a generally negative view of EWL. The following exemplifies the dominant attitude, in both places:

But the thought of me teaching 'til I'm 67, for another 12 years, that I can't see. I just think it would be too much of a toll on my body. (Edith, US teacher)

An Irish teacher was angry about the proposed increase in state pension age:

I think ... it is rotten to change it halfway through when you have something set in your head. I mean, if you're very young say and you're starting out working you don't care because you don't even imagine what you will be like at that age, but if you're ... coming up to retirement I think people shouldn't be forced to work longer than they want to work. I think it is very unfair on them. (Caitriona, Irish teacher)

Both teachers and health-care workers distinguished between the demands of more and less physically demanding work on EWL capacity:

If you've been drilling, doing manual labour, maybe your body is broken down by 60 , so maybe you need a different standard. Maybe our government should let you get things earlier. (Helen, US teacher)

It would be very hard to be lifting stuff like you used to, like a physical job is way harder when you're older. (Caitriona, Irish teacher)

Regardless of occupation or country, most of the older women interviewed believed that people should be able to look forward to some quality time following retirement:

I do not want to be one of those people who works 'til they die and walks in the parking lot and either works themselves to death or has some sort of health condition that they can't manage. (Hope, US teacher) 
I think it's bull. They want us to go from the job to the grave. They need to stop it. It's a bad idea. (Jenny, US HCW)

However, a few teachers and health-care workers would be willing to work after 65:

I'd happily continue until I'm 80. (Ingrid, US teacher)

People's health is a lot better and I think they'd be a lot more able to work and I think a lot of people would be glad to work ... If somebody told me I had to work until 68, I don't think I would freak it, you know. (Finola, Irish teacher)

One health-care worker, still working at age 70, felt others should have to work past age 65:

They need to be still out there working. It ain't gon' kill them. It didn't kill me, so let's keep them active. (Gemma, US HCW)

While one Irish health-care worker felt she personally could continue, she acknowledged others might not be able to:

I really think it's not just a one-size-fits-all ... And while I might be spared my health to work as long as I can, my friend wouldn't be, she wouldn't be physically able to work and I think it would be very unfair to expect her to work. (Jane, Irish $\mathrm{HCW}$ )

Several teachers appeared to have internalised claims that EWL is necessary to sustain pension systems:

I think it's necessary. So part of me is looking at the greater good of you know things of Social Security going broke and those kinds of things. (Ellie, US teacher)

The bottom line is the state cannot afford to be paying pensions for people for 20, 30 years. It's just not sustainable that people retire at 65 and then live for another

20 years. (Jasmine, Irish teacher)

Even having internalised the claims that pension systems were unaffordable and EWL was unavoidable, these teachers noted that people in physically onerous jobs should be able to retire earlier.

\section{Discussion}

A lifecourse framework shows that teachers and health-care workers have quite different work-life trajectories that turned on early adulthood experiences of education, employment and family formation. Teachers in both countries tended to come from families with strong advocacy and sufficient resources for third-level education, often having teachers as role models in kin networks. This set them on pathways to long and stable careers, often in one location or school. As teachers 
approached retirement, most expected adequate pensions, in part due to generous occupational pension schemes. The teachers interviewed were also usually in good health and, if not, their health issues were not work-related.

By contrast, the Irish and US health-care workers typically were not encouraged by parents or teachers to pursue further education or sometimes even to finish secondary school. This resulted in few qualifications or alternatives to a series of lowpaid jobs, often in the services sector or manufacturing in early adulthood, before forming families of their own. Several tried to pursue further education or nursing later, but by then they had children. Working, studying and bringing up children, particularly if they were single parents, was overwhelmingly difficult, so they did not succeed. This illustrates the difficulty of improving their financial position once the circumstances of early adulthood transitions - whether having to leave education, settle for limited occupational choices, or to care for children or older relatives - closes doors and constrains choices.

Despite many similarities, there were some notable differences between the US and the Irish health-care workers. Irish workers generally spent longer periods working unpaid in the home, caring for children, consistent with social norms and gender-discriminatory employment legislation of the day. Irish workers earned somewhat better pay and had more job protections, a by-product of Ireland's membership of the European Union. With almost no family-friendly policies, for US health-care workers the opportunity for extended periods outside employment to care for children was less; instead they juggled unstable low-paid employment and the daily tasks of family life and abandoned dreams of training for better jobs.

One expectation might be that EWL would be generally benign and unproblematic for workers like teachers, who had secure well-paid jobs that were not, at first glance, physically demanding. However, most of the teachers interviewed in both countries expressed strong resistance to being compelled to work past the traditional state pension age. This may be partly due to strong norms of teachers' retiring in their late fifties or early sixties, an early exit from employment influenced by the structure of the occupational pension system. In teachers' accounts, they frequently referred to the idea that working 35 or 40 years was 'long enough', alluding to the stressful nature of the job. Several drew explicitly on the notion that people deserve some years of healthy retirement, which resonates with previous research findings about perspectives on retirement elsewhere (Pond, Stephens and Alpass 2010).

The prospect of working up to age 67 is obviously daunting for those in lowpaid, physically demanding work that health-care workers experience. Several worried that their physical condition would prevent them doing their jobs at older ages. Some had already tried to adapt to declining physical abilities, moving from nursing homes to the somewhat less physically demanding home care setting. That enabled them to continue working, but at the cost of earning less and with less-predictable working conditions. For some health-care workers, such adjustments would be impossible, as that might imply working in unsafe neighbourhoods or without guarantees of enough hours to earn sufficient income (see also Stacey 2011). How or where such women could work, in the face of physical limitations that seem likely only to increase with age, is unclear, no matter what EWL policies seem to demand. The fact that EWL policies and restrictive health policies are often 
introduced simultaneously puts workers in physically demanding jobs in a disadvantageous position. This needs to be addressed by employer-led policies that allow people to retire or be re-deployed, as well as modifications to EWL policies raising the age of the state pension for these workers.

Their accounts illustrate the precariousness of employment in private healthcare agencies, which gives workers little control over their working hours or income. This highlights the extreme difficulty the combination of low wages and little job security causes for savings, state pension-building or private pension contributions (Ginn, Street and Arber 2001). The trend of individualisation of pensions in both US and Irish occupational pension policy makes matters worse (Ní Léime and Street 2016). Because health-care workers are usually almost completely dependent on Social Security and Irish state pensions, some believe they will need to continue working indefinitely to ensure financial survival. Their position will become progressively more difficult if the age for entitlement keeps climbing, as is currently happening. Taking women's perspectives into account, whether Irish or American, teachers or health-care workers, the overwhelming sense from the data they provided shows that - beyond merely opinions or normative beliefs - the women realise that they have worked hard to earn rights to adequate pensions and relief from compulsory employment later in life. For most of the women, efforts to extend working life represents no more than a broken promise that they had earned the right to retire in dignity at the end of an adult lifetime of work.

\section{Policy and research implications}

Instead of the one-size-fits-all policy of raising state pension age to a uniform age of 68 , the perspectives of older women health-care workers and teachers provide support for differentiated policies to account for the content of jobs and the structure of employment income and benefits, with a state pension that offers some compensatory features for the most vulnerable workers. Both teachers and health-care workers believed that workers in low-paid physically demanding jobs should receive the state pension/Social Security at an earlier age than those in less physically demanding, better paid and/or more secure jobs. Since the timing of early adulthood transitions indicated that many disadvantaged workers tended to start paid work at an earlier age (sometimes much earlier) than more securely employed and better-paid workers, earlier entitlement to pensions seemed only fair. The policy problem to be addressed was not necessarily the age of an individual retiring, but perhaps more equitably, the span of a working life and the demands made on it. Because low-paid precarious workers are already so heavily dependent on US Social Security and Irish state noncontributory pensions, and they earn too episodically or too little to contribute to private pensions in either place, it is obvious that the level of state pensions for vulnerable workers needs to be maintained or improved.

There are issues beyond the scope of this work that warrant further examination. For example, US health-care work is highly racialised, a long-standing occupational characteristic that needs further qualitative investigation to understand the intersections among gender, age, race and work-life trajectories (Duffy 2005; Stacey 2011). Similarly, more in-depth research is needed to investigate experiences of the recent influx of migrant care workers in Ireland. Such workers are often employed directly 
by families, and may be mainly or dominantly outside formal systems that could provide any rights to retirement income (Walsh and O'Shea 2009). Understanding more about racialised and migrant workforces is increasingly important for EWL.

Contrasting two categories of older women workers in two countries underscores unique features of the US and Irish occupational and policy landscapes. Irish women health-care workers in public service employment were unionised and had somewhat better pay and work conditions than their non-unionised private-sector US counterparts. Although Irish health-care workers in the private sector were less well paid and typically lacked occupational pensions, sick leave or job security, they did have paid holidays and so had somewhat better conditions than US workers. Teachers in both countries faced significantly better prospects for EWL and retirement than their health-care worker counterparts. Despite stark differences shaped by work-life trajectories and occupational realities, the prospect of EWL - even among women who have internalised the expectation that they must work longer - was an unpopular idea for most, actively feared by some and regarded as inequitable because it ignores the real-life circumstances of disadvantaged workers.

Critiques of EWL policies have explored inequalities of adult working lifecourses that are structured into employment relations, how those exacerbate negative effects of longer work for disadvantaged workers, and how gendered family and work norms systematically disadvantage women (Ní Léime et al. 2017). Restricting the analysis to older women highlighted instead other differences shaping prospects for EWL, filling a gap in lifecourse research by exploring intra-cohort variation (Hagestad and Dykstra 2016). Analysis of two very different occupational settings in two countries shows how family and occupation influence income, benefits and working conditions, layered atop unique national contexts that produce unequal outcomes among older women. This also highlights differences that protect some women workers, while putting many others at risk. Lifecourse-sensitive analysis reminds researchers and policy makers that, beyond national context or occupational circumstances, women's work-family trajectories are differentiated in ways that ensure that some well-employed women workers with stable families can choose whether and under what circumstances to extend working lives, while other women have little chance of avoiding the compulsion to try to earn, long past traditional retirement ages.

Acknowledgements. Á.N.L. gratefully acknowledges the generosity of the women and men who agreed to be interviewed for this project, and those who helped her recruit individual research participants.

Declaration of contribution of authors. Á.N.L.'s main contribution was in data collection in both countries, data analysis and interpretation and policy contextualisation in Ireland, and writing. D.S. contributed US-specific context, data analysis, and collaborated on the interpretation and write-up.

Statement of funding. The research on which this paper is based was supported by a Marie Curie International Outgoing Fellowship within the 7th European Community Framework Programme. This article is also based on work from COST Action IS1409, supported by COST (European Cooperation in Science and Technology). Funding from the State University of New York College of Arts and Sciences enabled the authors to collaborate on the paper. Funders played no role in the design, execution, analysis or interpretation of data or the writing of the study.

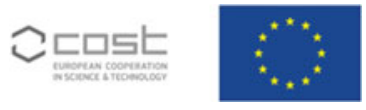


Statement of conflict of interest. Neither author has any conflicts of interest.

Statement of ethical approval. Ethical approval was obtained for the research from the Institutional Review Board at Case Western Reserve University (reference IRB-2015-1229) on 14 July 2016 and from the Research Ethics Committee at the National University of Ireland, Galway (REC reference 17-Jan-12).

\section{References}

Burgard SA, Brand JE and House JS (2007) Toward a better estimation of the effect of job loss on health. Journal of Health and Social Behavior 48, 369-384.

Cangiano A and Walsh K (2014) Recruitment processes and immigration regulations: the disjointed pathways to employing migrant carers in ageing societies. Work, Employment and Society 28, 372-389.

D'Addio A (2015) New OECD Data and Analysis Revealing the Wide Gap in Pension Benefits Between Men and Women. OECD Gender Portal, Gender Equality. Available online at http://www.oecd.org/gender/ data/newoecddataandanalysisrevealingthewidegapinpensionbenefitsbetweenmenandwomen.htm (Accessed 30 October 2017).

Dannefer D (2003) Cumulative advantage/disadvantage and the life course: cross-fertilizing age and social science theory. Journals of Gerontology: Psychological Sciences and Social Sciences 58B, S327-S333.

Dewilde C (2012) Life course determinants and incomes in retirement: Belgium and the United Kingdom compared. Ageing \& Society 32, 8, 587-615.

Doyle M and Timonen V (2009) The different faces of care work: understanding the experiences of the multi-cultural care workforce. Ageing \& Society 29, 337-350.

Duffy M (2005) Reproducing labor inequalities: challenges for feminists conceptualising care at the intersections of gender, race and class. Gender \& Society 19, 66-68.

Duffy M, Armenia A and Stacey C (2015) Caring on the Clock. The Complexities and Contradictions of Paid Care Work. New Brunswick, New Jersey: Rutgers University Press.

Duvvury N, Ní Léime Á, Callan A, Price L and Simpson M (2012) Older Women Workers' Access to Pensions: Vulnerabilities, Perspectives and Strategies. Galway, Ireland: National University of Ireland.

Folbre N (2012) For Love and Money: Care Provision in the United States. New York: Russell Sage Foundation.

Giele J and Elder G (1998) Life course research: development of a field. In Giele J and Elder G (eds), Methods of Life Course Research: Qualitative and Quantitative Approaches. Thousand Oaks, California: Sage pp. 5-27.

Ginn J and MacIntyre K (2013) UK pension reforms: is gender still an issue? Social Policy and Society, 13, 91-103.

Ginn J, Street D and Arber S (2001) Women, Work and Pensions: International Issues and Prospects. Buckingham, UK: Open University Press.

Grayson JL and Alvarez HK (2008) School climate factors relating to teacher burnout: a mediator model. Teaching and Teacher Education 24, 1349-1363.

Grenier A (2012) Transitions and the Life Course. Bristol, UK: Policy Press.

Hagestad G and Dykstra P (2016) Structuration of the life course: some neglected aspects. In Shanahan MJ, Mortimer JT and Johnson MK (eds), Handbook of the Life Course. Handbooks of Sociology and Social Research. New York: Springer, pp. 131-157.

Harrington Meyer M (2013) Changing Social Security in the US: rising insecurity? Social Policy and Society 12, 135-146.

Kerr RA, Breen J, Delaney M, Kelly C and Miller K (2011) A qualitative study of workplace stress and coping in secondary teachers in Ireland. Irish Journal of Applied Social Studies 11, Article 3. Available online at https://arrow.dit.ie/ijass/vol11/iss1/3 (Accessed 30 October 2017).

Lain D (2012) Working past 65 in the UK and the USA: segregation into 'Lopaq' occupations? Work, Employment \& Society 26, 78-94.

László KD, Pikhart H, Kopp MS, Bobak M, Pajak A, Malyutina S, Salavecz G and Marmot M (2010) Job insecurity and health: a study of 16 European countries. Social Science \& Medicine 70, 867-874.

Marmot M and Bell R (2010) Challenging health inequalities-implications for the workplace. Occupational Medicine 60, 162-166. 
McCaughey D, McGhan G, Kim J, Brannon D, Leroy H and Jablonski R (2012) Workforce implications of injury among home health workers: evidence from the National Home Health Aide Survey. Gerontologist 52, 493-505.

Munnell A (2013) Social Security's real retirement age is 70. Issue Brief 13-15, Center for Retirement Research at Boston College, Boston.

Neumark D, Burn I and Button P (2015) Is it harder for older workers to find jobs? New and improved evidence from a field experiment. NBER Working Paper 21669, National Bureau of Economic Research, Cambridge, Massachusetts.

Ní Léime Á, Street D, Vickerstaff S, Krekula C and Loretto W (eds) (2017) Gender, Ageing and Extended Working Lives: International Analysis from a Critical Perspective. Bristol, UK: Policy Press.

Ní Léime Á and Street D (2016) Gender and age implications of extended working life policies in the US and Ireland. Critical Social Policy 37, 464-483.

Organisation for Economic Co-operation and Development (OECD) (2006) Live Longer, Work Longer. Paris: OECD.

Organisation for Economic Co-operation and Development (OECD) (2018) Gender wage gap. Available online http://dx.doi.org/10.1787/7cee77aa-en (accessed 26 June 2018)

Pond R, Stephens C and Alpass F (2010) How health affects retirement decisions: three pathways taken by middle-older aged New Zealanders. Ageing \& Society 30, 527-545.

Roy D, Weyman A, George A and Hudson-Sharp N (2018) A qualitative study into the prospect of working longer for physiotherapists in the United Kingdom's National Health Service. Ageing \& Society 38, 1693-1714.

Russell J (2014) Social Insecurity, 401(k)s and the Retirement Crisis. Boston: Beacon Press.

Stacey CL (2011) The Caring Self: The Work Experience of Home Care Aides. Ithaca, New York: ILR Press. Stacey C and Ayers L (2015) Caught between love and money: the experiences of paid family caregivers. In Caring on the Clock. The Complexities and Contradictions of Paid Care Work. New Jersey: Rutgers University Press, pp. 201-212.

Standing G (2011) The Precariat: The New Dangerous Class. London: Bloomsbury Academic Press.

Street D and Tompkins J (2017) Is 70 the new 60? Extending American women's and men's working lives. In Ní Léime A, Street D, Vickerstaff S, Krekula C and Loretto W (eds), Gender, Ageing and Extended Working Lives: International Analysis from a Critical Perspective. Bristol, UK: Policy Press, pp. 195-217.

Timonen V and Doyle M (2007) Worlds apart? Public, private and non-profit sector providers of domiciliary care for older persons in Ireland. Journal of Aging Studies 21, 255-265.

Vosko LF (2008) Temporary work in transnational labour regulation: SER-centrism and the risk of exacerbating gendered precariousness. Social Indicators Research 88, 131-145.

Walsh K and O'Shea E (2009) The Role of Migrant Care Workers in Ageing Societies: Context and Experiences in Ireland. Galway, Ireland: National University of Ireland.

Zeytmoglu IU, Denton M, Davies S and Plenderleith JM (2009) Casualized employment and turnover intention: home care workers in Ontario, Canada. Health Policy 91, 258-268.

Cite this article: Ní Léime Á., Street D (2019). Working later in the USA and Ireland: implications for precariously and securely employed women. Ageing \& Society 39, 2194-2218. https://doi.org/10.1017/ S0144686X18000508 